\title{
The characteristics of citizen science in a fishbowl
}

\section{Gerid Hager $^{a, *}$, Barbara Kieslinger ${ }^{b, *}$, Susanne Hecker ${ }^{c}$ and Muki Haklay ${ }^{d}$}

a International Institute for Applied Systems Analysis,

Schloßplatz, Laxenburg, Austria

$b$ Centre for Social Innovation,

Linke Wienzeile, Vienna, Austria

c Leibniz Institute for Evolution and Biodiversity Science, Museum für Naturkunde, Invalidenstraße, Berlin, Germany

d University College London,

Gower St, London, United Kingdom

E-mail: hager@iiasa.ac.at, kieslinger@zsi.at, susanne.hecker@mfn.berlin, m.haklayaucl.ac.uk

This paper reports on a workshop during the Austrian Citizen Science Conference 2020 that allowed discursive conversation about the reasoning and the formation of opinions around assessing short case descriptions as citizen science, or not. Debater's opinions on cases seemed fluid and often changed when new information became available. Hence, the discussions highlighted that the understanding of Citizen Science is fluid and dynamically evolving as we speak. 


\section{Introduction}

In 2019, the EU-Citizen.Science ${ }^{1}$ project needed a shared reference and definition of citizen science (CS) for developing quality criteria for CS resources on the EU-Citizen.Science platform. In parallel, the European Citizen Science Association (ECSA) was approached by the Open Science Policy Platform to provide guidelines on CS for the development and practical implementation of open science policy at EU-level. Despite this recurring need for a common description, many CS definitions are presently used side-by-side [1]. A consolidated definition is lacking and the complexities of finding a shared understanding have been widely discussed (cf. [2-4]). Therefore, ECSA and the partners in the EU-Citizen.Science project formed a working group to develop a CS characterisation that would acknowledge and reflect the diversity of views of CS across disciplines. The aim was to enable different stakeholders to use the most relevant aspects for their particular contexts, without compromising the essence of CS.

The CS characterisation was approached through ten overarching factors for CS (such as activeness, compensation, data sharing) and 61 sub-factors which were then turned into 50 short case descriptions (vignettes, identifiable by a random persona name such as "Janis") to represent 5 clear cases of CS, 5 clear cases of not-CS and 40 ambiguous cases. The vignettes were presented in a survey in December 2019, asking respondents to rate them on a scale from 'not citizen science' $(0 \%)$ to 'citizen science' $(100 \%)$ and to provide explanations for their assessment. Over 330 people responded to the survey, with more than 5,000 ratings and around 50,000 words of textual comments [5]. While this allowed quantitative analysis and qualitative comparative analysis of individual rationales for the ratings, the survey did not allow for discursive questioning and conversation to better understand the reasoning behind the individual assessments and the formation of these opinions.

Hence, during the Austrian Citizen Science Conference in September 2020, we organised a workshop to spark interactive conversations on a set of selected vignettes (namely: Jane, Jacque, Dorota, Erik, Sebastian, Yanis) that had been developed with controversies and grey areas built into them. The aim was to scope for un- or underexplored areas in the characterisation work and to gather material for further hypothesis forming for follow-up research.

\section{Method}

To gain deeper insight into the perception of vignettes and observe the unfolding discussion we opted for a mixed workshop design. The workshop was held online and in German, using the Edudip conference software. It lasted one hour and was attended by 20 participants. Gerid Hager and Barbara Kieslinger chaired the workshop, Susanne Hecker moderated the chat. The discussions were documented using personal notes. The chat was saved as text for reference.

The workshop started with an activity resembling the vignette survey in a mini-format. Six of the 50 vignettes were translated into German (cf. Figure 1) and made available to the participants. They filled in a short online survey, sharing to what extent they deemed the vignettes to be CS. The results were shown during the subsequent presentation [6]. The discussion around the individual vignettes was organised as "speed fishbowl" sessions, with each vignette assigned

${ }^{1} \underline{\mathrm{https}: / / \mathrm{eu}-\mathrm{citizen} . \text { science/ }}$ 
to one fishbowl. Workshop participants signed up to the fishbowls and discussed the cases during $\sim 10$ min slots, one fishbowl after another so that everyone could contribute in the chat or jump into the fishbowl to make direct contributions. The discussions were followed by a feedback round. Subsequently, the ECSA Characteristics of Citizen Science were presented. The workshop ended with a short Q\&A session.

\begin{tabular}{|c|c|}
\hline Original vignette (EN) & Translated vignette (DE) \\
\hline $\begin{array}{l}\text { Erik is a teacher in Uppsala, Sweden. For the past } \\
\text { I5 years, he is running a weather station that is } \\
\text { part of the Weather Underground's Personal } \\
\text { Weather Station Network with over } 250,000 \\
\text { participants who share their observation data, } \\
\text { just like Erik. In return for the data sharing, the } \\
\text { company is providing tech support, data } \\
\text { management services and customised, } \\
\text { free-of-charge access to forecasts. The company } \\
\text { uses the data to produce a global weather forecast } \\
\text { as a commercial service. }\end{array}$ & $\begin{array}{l}\text { Erik ist Lehrer in Uppsala, Schweden. Seit I5 } \\
\text { Jahren betreibt er eine Wetterstation, die Teil des } \\
\text { Personal Weather Station Networks der Firma } \\
\text { Weather Underground ist, mit über 250.ooo } \\
\text { Teilnehmern, die alle ihre Beobachtungsdaten } \\
\text { teilen, genau wie Erik. Als Gegenleistung für den } \\
\text { Datenaustausch bietet das Unternehmen } \\
\text { technischen Support, Datenverwaltungsdienste } \\
\text { und maßgeschneiderten, kostenlosen Zugriff auf } \\
\text { Prognosen. Das Unternehmen verwendet die } \\
\text { Daten, um eine globale Wettervorhersage als } \\
\text { kommerziellen Dienst zu erstellen. }\end{array}$ \\
\hline
\end{tabular}

Figure 1: Example of a vignette ("Erik") translated for the workshop

\section{Results}

Eleven workshop participants responded to the mini-survey. The quantitative results on the six selected vignettes showed overlap with the original survey results. The workshop participants assessed Janet's case towards "not being CS", Sebastian's case towards "being CS" and provided a variation of responses regarding Jacque's, Dorota's and Erik's cases across the entire scale (cf. Figure 2). From the workshop participant's point of view, Yanis' case was tending towards "not being CS".

We could also observe argumentative overlap between the fishbowl discussion and the qualitative text responses from the survey, especially regarding the chosen focus on factors and topics. For example, aspects of commercialisation, sharing of personal biological data or degrees of engagement and awareness fuelled the workshop debates. These were also themes of controversy in the vignette survey responses [5].

The online environment of the workshop also enabled parallel discussions in the chat which focused on the methodology of the survey, revealing additional insights. Suggestions were made to consider the vignette's readability and comprehensibility in different languages and cultural contexts, and to test different levels of readability/comprehensibility across the set of 50 vignettes to highlight potential unevenness. 


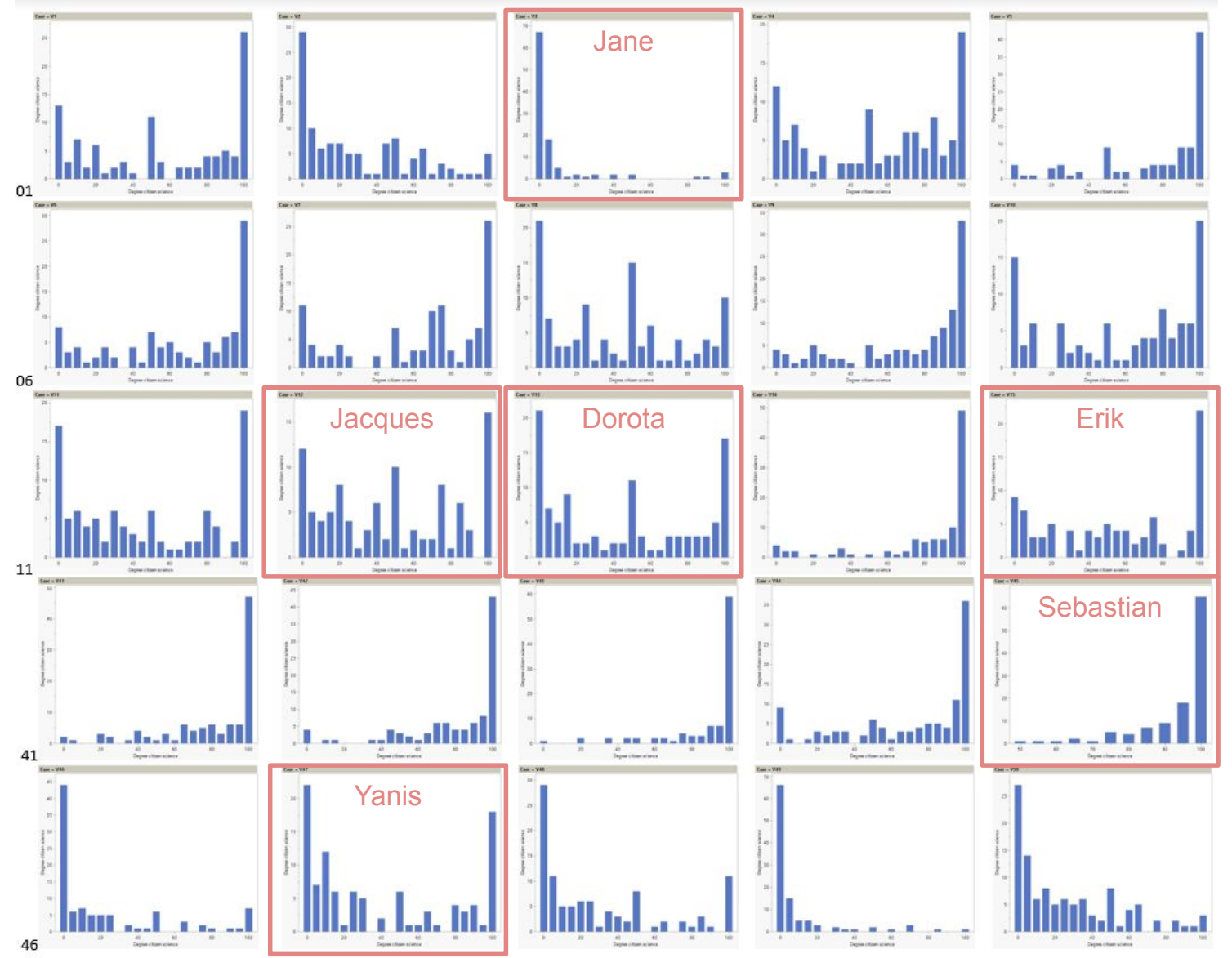

Figure 2: Selected results of vignette survey - degree of CS (0-100\%) [6], vignettes chosen for workshop activity marked in red.

Most importantly, the discussions revealed that, while debaters often started with different viewpoints and opinions, a more nuanced understanding of a case only developed during the discussion. Opinions and initially shared understandings of whether a case is or is not CS changed. The focus often shifted from debating "Is this CS or not?" to "These aspects are actually difficult to judge without more information", or to "I find these factors are more relevant than others, but it also depends if other factors come into play". Feedback from participants at the end of the session underlined the importance of the discussion to illuminate one's "own black spots" or aspects that one did not pay attention to. It also helped identify information that was lacking in the case description and that would help participants to judge them properly.

\section{Discussion and conclusion}

Though the results of the vignette survey seem to be replicable with small groups of people, we still lack understanding of why and how people make their assessments. This workshop provided interactive exploration into people's fluid reasoning, methodological considerations of the design of vignettes, the interconnected nature of factors and the role of discourse in developing a robust viewpoint on the cases.

The speed-fishbowl discussions suggest nuanced dependencies across factors. Debater's opinions on cases seemed fluid and often changed when new information on other factors became 
available. This poses a potential limitation of vignettes that focus on certain factors but lack information on others. One case may be regarded both CS and not CS by the same person, depending on the combination of factors presented. It also highlights that the weight of factors is relative and may change in relation to other factors. This area needs to be investigated further and we plan to conduct similar workshops in the future. Furthermore, tests with different formulations of the same case could help illuminate these potential description biases.

Language and cultural aspects also need further consideration in the vignette's formulations while balancing the details of the vignettes and the efforts required from participants to read them as part of a study. Other potential applications of the vignettes lie in training and teaching about $\mathrm{CS}$, or in developing a comparative, multilingual study of perceptions on CS. The discussions during the fishbowl highlighted that the understanding of CS is fluid and dynamically evolving as we speak, and practitioners and scholars of CS have the opportunity to nurture a culture of openness and acknowledge the plurality of these perceptions.

\section{Acknowledgements}

EU-Citizen.Science received funding from the EU's Horizon 2020 research and innovation programme under grant agreement No. 824580 . We thank the working group as outlined here: https://zenodo.org/record/3758668\#.X8Z2GZNKhTY

\section{References}

[1] Haklay M, Hulbert J, Shanley L (2019) lshanley/CitSciDefinitions: Citizen Science Definitions. https://github.com/lshanley/

[2] Auerbach J et al. (2019) The problem with delineating narrow criteria for citizen science. Proceedings of the National Academy of Sciences 116, 15336-15337.

[3] Eitzel M et al. (2017) Citizen science terminology matters: exploring key terms. Citizen Science: Theory and Practice 2.

[4] Heigl F et al. (2019) Opinion: Toward an international definition of citizen science. Proceedings of the National Academy of Sciences 116, 8089-8092.

[5] Haklay M et al. (2020) Contours of Citizen Science: A Vignette Study. SocArXiv $10.31235 /$ osf.io/6u2ky.

[6] Hager G, Kieslinger B (2020) Würden Sie das Citizen Science nennen? Österreichische Citizen Science Konferenz 2020. http://pure.iiasa.ac.at/16736 